\title{
The effect of silica on polymorphic precipitation of calcium carbonate: an on-line energy-dispersive $X$-ray diffraction (EDXRD) study'
}

\author{
Matthias Kellermeier, ${ }^{\text {*a }}$ Fabian Glaab, ${ }^{\mathrm{b}}$ Regina Klein, ${ }^{\mathrm{b}}$ Emilio Melero-García, \\ Werner Kunz ${ }^{b}$ and Juan Manuel García-Ruiz ${ }^{* c}$
}

\begin{abstract}
Calcium carbonate is the most abundant biomineral and a compound of great industrial importance. Its precipitation from solution has been studied extensively and was often shown to proceed via distinct intermediate phases, which undergo sequential transformations before eventually yielding the stable crystalline polymorph, calcite. In the present work, we have investigated the crystallisation of calcium carbonate in a time-resolved and non-invasive manner by means of energy-dispersive $\mathrm{X}$-ray diffraction (EDXRD) using synchrotron radiation. In particular, the role of silica as a soluble additive during the crystallisation process was examined. Measurements were carried out at different temperatures $(20,50$ and $80^{\circ} \mathrm{C}$ ) and various silica concentrations. Experiments conducted in the absence of silica reflect the continuous conversion of kinetically formed metastable polymorphs (vaterite and aragonite) to calcite and allow for quantifying the progress of transformation. Addition of silica induced remarkable changes in the temporal evolution of polymorphic fractions existing in the system. Essentially, the formation of calcite was found to be accelerated at $20{ }^{\circ} \mathrm{C}$, whereas marked retardation or complete inhibition of phase transitions was observed at higher temperatures. These findings are explained in terms of a competition between the promotional effect of silica on calcite growth rates and kinetic stabilisation of vaterite and aragonite due to adsorption (or precipitation) of silica on their surfaces, along with temperature-dependent variations of silica condensation rates. Data collected at high silica concentrations indicate the presence of an amorphous phase over extended frames of time, suggesting that initially generated ACC particles are progressively stabilised by silica. Our results may have important implications for $\mathrm{CaCO}_{3}$ precipitation scenarios in both geochemical and industrial settings, where solution silicate is omnipresent, as well as for $\mathrm{CO}_{2}$ sequestration technologies.
\end{abstract}

\section{Introduction}

Calcium carbonate is one of the most important and abundant minerals on Earth. It occurs in large amounts in sedimentary and evaporitic rocks, ${ }^{1}$ and is a major component of the inorganic-organic hybrid structures found in the tissues of many

aPhysical Chemistry, University of Konstanz, Universitätsstrasse 10, D-78457 Konstanz, Germany. E-mail: matthias.kellermeier@uni-konstanz.de; Fax: +49 7531 88 3139; Tel: +497531882001

${ }^{b}$ Institute of Physical and Theoretical Chemistry, University of Regensburg, Universitätsstrasse 31, D-93040 Regensburg, Germany. E-mail: werner.kunz@ chemie.uni-regensburg.de; Fax: +49941943 4532; Tel: +499419434044

${ }^{c}$ Laboratorio de Estudios Cristalográficos, Instituto Andaluz de Ciencias de la Tierra, CSIC-Universidad de Granada, Av. de las Palmeras 4, E-18100 Armilla (Granada), Spain.E-mail:jmgruiz@ugr.es; Fax: +34 958 181632; Tel: +34 958181644

$\dagger$ Electronic supplementary information (ESI) available: Additional figures and tables (Section S1), details on experimental procedures and data evaluation routines (Section S2), discussion of $\mathrm{pH}$ data (Section S3), 2D and 3D plots of EDXRD patterns for all investigated silica concentrations and temperatures (Section S4). See DOI: 10.1039/c3nr00301a living organisms. ${ }^{2}$ In industry, $\mathrm{CaCO}_{3}$ finds broad applications as a filler or ingredient of construction materials, ${ }^{3}$ but is also responsible for serious problems caused by incrustation and scaling in flow devices and water pipelines due to spontaneous precipitation at elevated temperatures. ${ }^{4}$

When precipitated from aqueous solution, calcium carbonate does usually not crystallise directly in the stable calcite modification (vaterite and aragonite being the metastable crystalline polymorphs), but often undergoes multiple phase transitions under kinetic control along a series of intermediates towards increasing stability. ${ }^{5}$ At room temperature, the phase sequence amorphous calcium carbonate (ACC) $\rightarrow$ vaterite $\rightarrow$ calcite has frequently been observed, ${ }^{6-8}$ though earlier liquid-like precursors to $\mathrm{ACC}^{7,9-11}$ and even prenucleation cluster species were also reported. ${ }^{12}$ The occurrence and lifetime of a particular phase was found to depend strongly on the chosen experimental parameters like supersaturation, $\mathrm{pH}$, agitation or the mixing procedure..$^{13}$ Temperature is another key factor in the determination of which polymorph is generated and for how long it persists in contact with a solution. Previous 
studies have demonstrated that heating favours the formation of aragonite. ${ }^{14-16}$ While co-existing with vaterite during the early stages of precipitation at $40-70{ }^{\circ} \mathrm{C},{ }^{6,14}$ more or less pure aragonite is initially obtained above $80{ }^{\circ} \mathrm{C},{ }^{14-16}$ which subsequently transforms into calcite upon ageing and thus replaces vaterite as a metastable intermediate in the crystallisation of $\mathrm{CaCO}_{3}$ at higher temperatures. ${ }^{6}$

Control over the multiple stages of $\mathrm{CaCO}_{3}$ precipitation under various conditions is truly a demanding task but at the same time represents one of the major goal of studies across various fields, as it would allow, among others, for tuning the properties of advanced materials ${ }^{17}$ or avoiding deposition of hard mineral scale. ${ }^{18}$ Accordingly, there have been numerous attempts to steer the progress of crystallisation, often making use of soluble additives that will interact with one or more of the intermediate phases, potentially leading to novel structures with interesting features and defined polymorphism. ${ }^{19}$ The vast majority of these approaches relies on the action of certain organic molecules, which appears a quite natural choice when considering the sheer unlimited structural diversity of such compounds and their important role in $\mathrm{CaCO}_{3}$ biomineralisation..$^{20}$ In turn, there are comparatively few reports on distinct effects observed in the presence of simple inorganic species. A fairly well documented example in this context is the influence of magnesium ions on the crystallisation of $\mathrm{CaCO}_{3}$, which has been investigated in detail due to the abundance of $\mathrm{Mg}^{2+}$ in seawater ${ }^{21}$ and the fact that these cations seem to be involved in the formation of many $\mathrm{CaCO}_{3}$ biominerals. ${ }^{22}$ On the other hand, it is surprising to note that another virtually ubiquitous inorganic species is much less characterised with respect to its possible impact on $\mathrm{CaCO}_{3}$ precipitation: silica, either in its amorphous or one of the crystalline phases, is a material extremely widespread in geological environments $\mathrm{s}^{23}$ and occurs in large amounts as a constituent of biomineralised skeletons. ${ }^{24}$ Consequently, many of the geochemical solutions from which calcium carbonate precipitates contain dissolved silica at concentrations that might affect nucleation, growth, polymorphism, texture, and final habit of crystalline particles formed under these conditions. ${ }^{25}$ This is particularly true for alkaline waters, which can be highly concentrated in silica because its solubility increases exponentially with $\mathrm{pH}$ at values higher than $c a .8 .5 .^{26}$ Significant amounts of dissolved silicate species are therefore also expected for solutions in contact with man-made cement structures as well as for most of the geochemical settings currently considered good candidates for carbon dioxide sequestration. ${ }^{27}$ In both cases, carbonation (i.e. $\mathrm{CaCO}_{3}$ formation) will occur in the presence of silica, which hence may influence the deterioration of concrete components and the efficiency of sequestration technologies. In this regard, it seems obvious that a much better understanding of the role of silica as an additive during precipitation of calcium carbonate is required.

Previous studies have shown that silica can affect the crystallisation of $\mathrm{CaCO}_{3}$ in different ways. In terms of final morphology and structure, it was found that complex single crystals of calcite with unusual symmetries can be grown in silica gels under ambient conditions, ${ }^{28}$ while biomimetic aggregates of aragonite nanocrystals were obtained by seeding ${ }^{29}$ or raising the temperature..$^{30}$ Other work provided evidence that dissolved silicate ions propel the growth of calcite and thus shift polymorphic ratios for its benefit. ${ }^{31,32}$ Regarding interactions with precursor phases, it was demonstrated that silica can effectively stabilise transient ACC by spontaneously precipitating around growing nanoparticles, thus building shells which impeded re-dissolution and phase transformation. ${ }^{33}$ Subsequent gradual release of $\mathrm{CaCO}_{3}$ units from the silica-ACC depots moreover led to self-assembly of needle-like calcite crystallites. ${ }^{34}$ Silica-mediated protection of ACC against crystallisation indeed appears to play a direct role in biomineralisation too, as the thermal stability of the ACC component in the cystoliths of certain plant leaves was found to increase with their silica content. ${ }^{35}$ Finally, it was shown that silicate species can also bind to solute ion clusters existing in $\mathrm{CaCO}_{3}$ solutions prior to nucleation, thereby regulating the rate and degree of cluster aggregation. ${ }^{36}$

Thus, while insight has been gained into the effects of silica on both the early (prenucleation clusters, ACC) and late (calcite growth, self-assembly of nanoparticles, morphogenesis) stages of $\mathrm{CaCO}_{3}$ crystallisation, information on possible interactions with intermediate phases (in particular the metastable polymorphs vaterite and aragonite) and their conversion to stable calcite is still strongly limited. Here, we have used synchrotron energy-dispersive X-ray diffraction (EDXRD) to monitor, in situ and in real time, crystallisation of calcium carbonate in the presence of solution silicate. Experiments were performed at different temperatures $\left(20,50\right.$ and $\left.80{ }^{\circ} \mathrm{C}\right)$ and varying silica contents, in order to study the influence of the additive on the relative stability of ACC, vaterite, and aragonite, as well as their rates of transformation and final polymorph selection under distinct conditions.

\section{Results}

\section{Crystallisation of calcium carbonate in the absence of silica}

Following the crystallisation of $\mathrm{CaCO}_{3}$ by means of EDXRD in $250 \mathrm{mM}$ suspensions without added silica resulted in sequential diffraction patterns as shown in Fig. 1. It is obvious that, at all studied temperatures, large amounts of crystalline material were formed already within 5 min after mixing, when the first spectrum was acquired. This is in line with the evolution of $\mathrm{pH}$ traced for the sample at $20{ }^{\circ} \mathrm{C}$, which indicates that transformation of initially generated amorphous particles to crystalline polymorphs is completed during that interval (see Fig. S1 and Table S1 in the ESI, and Section S3 for a corresponding discussion $\dagger$ ). The period over which ACC persists in neat solutions without silica is relatively short as compared to previous in situ diffraction studies (where purely amorphous phases were detected at the beginning), ${ }^{\mathbf{1 0 , 3 7 - 4 1}}$ probably due to different synthesis conditions in terms of $\mathrm{pH}$, concentrations, and/or mixing procedure.

At both 20 and $50{ }^{\circ} \mathrm{C}$, calcite and vaterite co-exist in noticeable fractions at the beginning. Interestingly, the vaterite signals after $\sim 5 \mathrm{~min}$ are clearly stronger at $50{ }^{\circ} \mathrm{C}$ than at $20{ }^{\circ} \mathrm{C}$, whereas the intensity of calcite reflections is much lower at the 

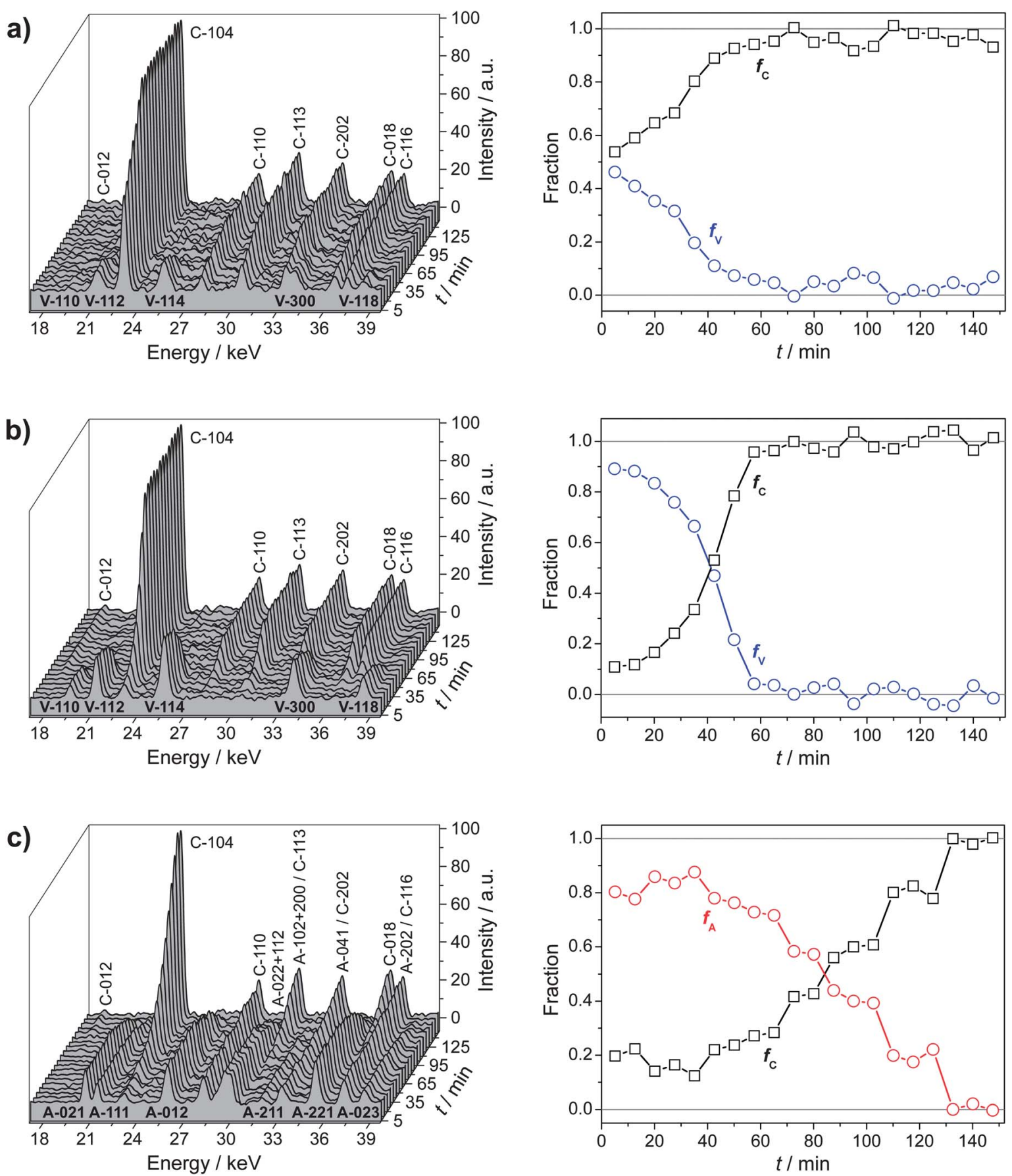

Fig. 1 Time-resolved EDXRD monitoring of $\mathrm{CaCO}_{3}$ crystallisation in solutions containing $250 \mathrm{mM}$ solutions each of $\mathrm{CaCl}_{2}$ and $\mathrm{Na}_{2} \mathrm{CO}_{3}$ at a temperature of (a) $20^{\circ} \mathrm{C}$, (b) $50^{\circ} \mathrm{C}$, and (c) $80^{\circ} \mathrm{C}$. Left: 3D representations of the collected diffraction patterns, in which occurring reflections are assigned to one or, in the case of overlapping peaks, several crystal planes belonging to the distinct polymorphs and characterised by the respective Miller indices. Right: temporal progressions of the relative fractions of calcite (black squares) and vaterite (blue circles) in samples at $20^{\circ} \mathrm{C}$ and $50^{\circ} \mathrm{C}$, and of calcite and aragonite (red circles) at $80^{\circ} \mathrm{C}$.

higher temperature (Fig. 1a and b). At $80{ }^{\circ} \mathrm{C}$, the major phase present in the first pattern is aragonite, with relatively small amounts of calcite (small 104 peak) and no vaterite being discernible (Fig. 1c). This confirms that aragonite is the preferential kinetic product formed at elevated temperatures, as reported previously. ${ }^{6,14-16,30}$ As time proceeds, the heights of peaks belonging to the respective metastable polymorph decrease gradually at all three temperatures. Concurrently, calcite reflections grow in intensity to reach a constant level once signals of vaterite/aragonite have vanished; this suggests that polymorph transformations take place progressively in the bulk solution. To quantify the progress of conversion, the fractions of calcite $\left(f_{\mathrm{C}}\right)$ and vaterite/aragonite $\left(f_{\mathrm{V}} / f_{\mathrm{A}}\right)$ at a given time were calculated from the data (see Section S2 in the ESI $\dagger$ ). The resulting values are outlined as a function of time in Fig. 1. Apparently, an approximately constant fraction of calcite was 
achieved after $\sim 40 \mathrm{~min}$ at $20{ }^{\circ} \mathrm{C}$, while taking almost $60 \mathrm{~min}$ at $50{ }^{\circ} \mathrm{C}$ and more than $130 \mathrm{~min}$ at $80{ }^{\circ} \mathrm{C}$.

Thus, the period required for the transformation of the metastable polymorph to be completed is the longer the higher the temperature. In principle, this is in conflict with the reported increase in the rate of calcite growth with temperature, which - in seeded solutions - was found to be the rate-determining step during transformation and hence caused the conversion of both vaterite and aragonite to become faster with increasing temperature. ${ }^{42,43}$ However, Ogino et al. observed an inverse trend in experiments carried out by direct mixing of $\mathrm{CaCl}_{2}$ and $\mathrm{Na}_{2} \mathrm{CO}_{3}$ in the absence of seed material. ${ }^{6}$ They interpreted their findings in terms of the effective surface area available for growth: as the solubility of the metastable crystalline phases decreases more steeply with increasing temperature than that of calcite, the supersaturation of the solutions with respect to calcite will be reduced and thus the number of growing calcite crystals should become lower towards higher temperatures. We infer that such effects also account for the present results, since we observed the same tendency in the rate of conversion and even obtained similar ratios for the relative duration of quantitative transformation to calcite (being $\sim 3.25$ times faster at $20{ }^{\circ} \mathrm{C}$ than at $80{ }^{\circ} \mathrm{C}$ in this work, as compared to a factor of 3-6 noted in the earlier study). ${ }^{6}$ Interestingly, the only existing in situ EDXRD data on $\mathrm{CaCO}_{3}$ crystallisation suggested an opposite scenario, as intermediate vaterite persisted in solution for longer periods at lower temperatures in a similar experimental setup. ${ }^{37}$ Even though higher concentrations were used in the previous study (500 vs. $250 \mathrm{mM}$ in our work), the main difference to the present measurements was clearly the range of temperatures investigated $\left(7.5-25{ }^{\circ} \mathrm{C}\right.$ vs. $\left.20-80{ }^{\circ} \mathrm{C}\right)$. This indicates that there is a crossover in the tendency of transformation rates near ambient temperature. Since the effective duration of conversion in unseeded systems appears to be determined by a competition of calcite growth rates and supersaturation, an explanation for these circumstances could be that changes in the solubility of the different $\mathrm{CaCO}_{3}$ polymorphs are relatively small between 7.5 and $25{ }^{\circ} \mathrm{C}$, whereas they become much more pronounced towards higher temperatures. ${ }^{\mathbf{4 4}}$

\section{Effect of added silica on $\mathrm{CaCO}_{3}$ polymorphism}

In order to facilitate a comparison of diffraction data recorded in the presence of silica to those acquired for neat $\mathrm{CaCO}_{3}$ suspensions, a virtual reaction progress $\alpha$ meant to reflect the degree of conversion to calcite at a given time was calculated ( $\alpha=1$ for complete transformation; note that $\alpha$ and the polymorphic fractions $f_{\mathrm{C}}$ and $f_{\mathrm{V}} / f_{\mathrm{A}}$ contain equal information, which however is derived in different ways, as $\alpha$ results directly from calcite signals while the determination of $f$ also involves reflections from the respective metastable polymorph; see Section S2 in the ESI $\dagger$ ). The corresponding values and the fractions of the respective metastable polymorph are shown in Fig. 2 for samples at different silica concentrations and temperatures.

$20{ }^{\circ} \mathrm{C}$. Addition of 200 and $600 \mathrm{ppm} \mathrm{SiO}_{2}$ at $20{ }^{\circ} \mathrm{C}$ (Fig. 2a) does not apparently affect the crystallisation process to a significant extent (except for certain differences in the progressions of $f_{\mathrm{V}}$ with time). In turn, when further increasing the silica content, marked changes can be discerned: at both 1200 and $2000 \mathrm{ppm} \mathrm{SiO}_{2}$, the fraction of vaterite is extremely low straight after mixing and the conversion to calcite appears to be largely completed already after the first or second EDXRD run. Accordingly, diffraction patterns exhibit hardly any variations with time from the very beginning, as exemplified for the sample at 1200 ppm in Fig. 3a (see Section S4 in the ESI for EDXRD data of different silica contents $\dagger$ ). This suggests that, in the concerned range of concentrations, added silica promotes the formation of calcite while inhibiting or leaving unaffected growth rates of vaterite and aragonite. A similar influence of silica on the polymorphism of calcium carbonate has been recognised in previous studies and was tentatively ascribed to reduced nucleation barriers for calcite. ${ }^{31,32}$ Recent AFM studies further revealed that promotion of calcite growth rests upon enhanced two-dimensional nucleation on the (104) face due to adsorbed negatively charged silica colloids which attract $\mathrm{Ca}^{2+}$ ions, as well as reinforced kink generation and propagation caused by the attachment of small mono- and oligomers to step edges. ${ }^{45}$ The latter phenomenon turned into an inhibitory effect at higher silica concentrations, which was however not observed in the present work (higher silica contents are discussed below).

At this point, it is important to consider the possible role of the bulk $\mathrm{pH}$ in the phase selection process. Corresponding data (see Fig. $\mathrm{S} 1$ in the ESI $\dagger$ ) show that $\mathrm{CaCO}_{3}$ precipitation takes place at a more or less constant $\mathrm{pH}$ level in all silica-containing systems (after an initial induction period of typically $\leq 20 \mathrm{~min}$ ). Nevertheless, the particular $\mathrm{pH}$ values of the various samples differ significantly, which might cause changes in the progress of crystallisation that are not related to the influence of silica. For example, precipitation at $1200 \mathrm{ppm} \mathrm{SiO}_{2}$ takes place at a noticeably higher $\mathrm{pH}(\sim 9.5)$ than at $600 \mathrm{ppm}(\sim 8.9$; $c$. Table $\mathrm{S} 1$ in the ESI $\dagger$ ). Since the fraction of $\mathrm{CO}_{3}{ }^{2-}$ ions in equilibrium rises with the $\mathrm{pH}$ of the solution, ${ }^{33}$ the supersaturation of $\mathrm{CaCO}_{3}$ will increase with the silica content. This is expected to result in higher nucleation rates for all $\mathrm{CaCO}_{3}$ polymorphs. However, it is well known that an increase in supersaturation usually leads to larger fractions of vaterite upon initial precipitation, ${ }^{6}$ contrary to what is observed. On the other hand, the transformation of vaterite to calcite should not be affected by the $\mathrm{pH}$ as such, because the supersaturation for calcite during this process is controlled by the solubility product of vaterite and does not depend on $\mathrm{pH}$, at least in the given range. ${ }^{42}$ In this regard, we consider changes in $\mathrm{CaCO}_{3}$ supersaturation with varying $\mathrm{pH}$ to be irrelevant for the later course of crystallisation, and thus conclude that the presence of silica is responsible for the traced effects.

In turn, the bulk $\mathrm{pH}$ also influences the chemistry of silica in solution; typically, the silica speciation is shifted towards lower oligomers with higher numbers of negative charges as the $\mathrm{pH}$ is raised. ${ }^{26}$ This could help in promoting calcite growth at silica contents of 1200 and $2000 \mathrm{ppm}$, which requires negatively charged silicate species to attract $\mathrm{Ca}^{2+}$ and lower oligomers to induce kink formation. ${ }^{45}$ Finally, it is worth mentioning that addition of sodium silicate causes an increase in total ionic 
a)

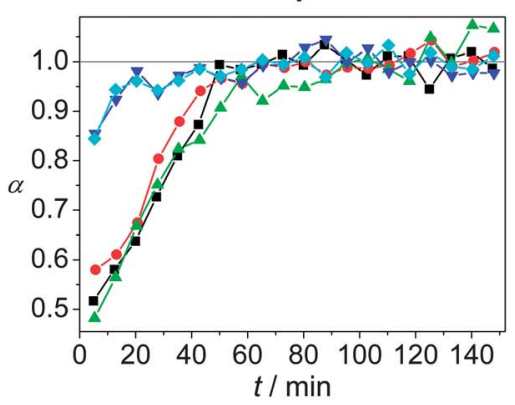

b)

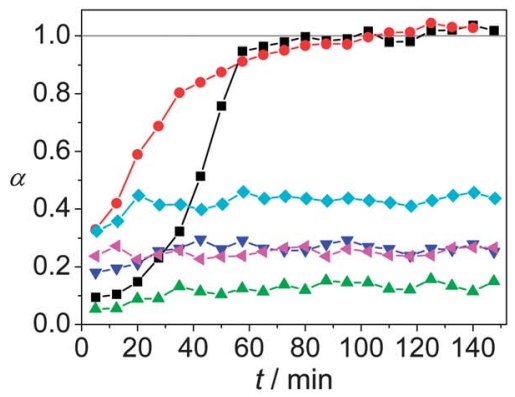

c)

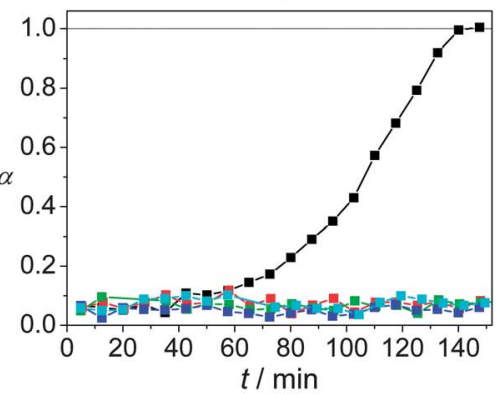

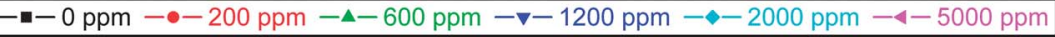
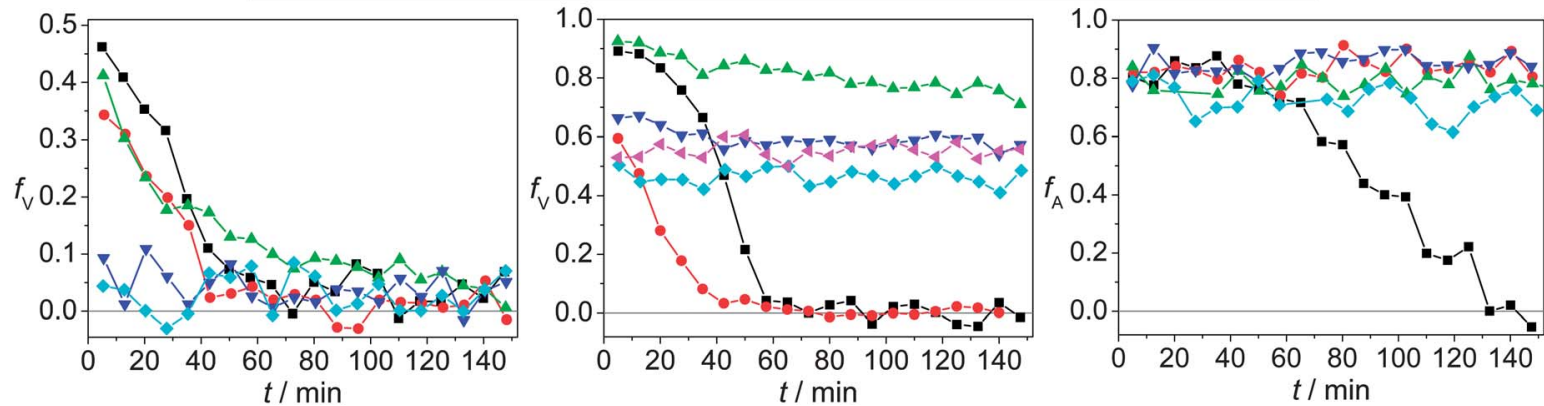

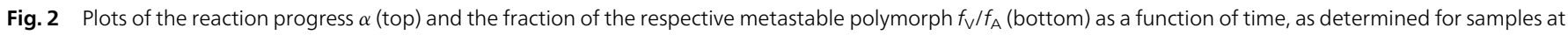
different silica concentrations and a temperature of (a) $20^{\circ} \mathrm{C}$, (b) $50^{\circ} \mathrm{C}$, and (c) $80^{\circ} \mathrm{C}$.

strength as compared to the reference experiment, which might alter the crystallisation process to some degree. However, since all studied samples already contain a considerable amount of background electrolyte $\left(0.5 \mathrm{M} \mathrm{NaCl}\right.$, originating from the $\mathrm{CaCl}_{2}$ and $\mathrm{Na}_{2} \mathrm{CO}_{3}$ solutions used for mixing) and the increment in salinity provoked by silica in the lower concentration regime is rather small (ca. $20 \mathrm{mM}$ additional ionic strength at $2000 \mathrm{ppm}$ $\mathrm{SiO}_{2}$ ), any such effects can be regarded negligible. Moreover, it has been reported that the rates of $\mathrm{CaCO}_{3}$ precipitation ${ }^{46}$ and vaterite-to-calcite transformation ${ }^{42}$ are both not sensitive to variations in ionic strength over a large range of salinities, so that this parameter should also not become important at higher silica contents.

$50{ }^{\circ} \mathbf{C}$. When the temperature is raised to $50{ }^{\circ} \mathrm{C}$ (Fig. 2b), the presence of only $200 \mathrm{ppm} \mathrm{SiO}_{2}$ already seems to have a related impact on polymorph selection and transformation kinetics as at $20^{\circ} \mathrm{C}$, since lower fractions of vaterite were detected relative to the silica-free reference during the stage where calcite and vaterite co-exist. On the other hand, the period required for conversion to be virtually quantitative is about the same in both cases, indicating that generated vaterite was temporarily stabilised by silica. This effect becomes drastically more pronounced with increasing silica concentration: at $600 \mathrm{ppm} \mathrm{SiO}_{2}$, the fraction of vaterite decreases only slightly with time and is as high as $80-90 \%$ over the entire period monitored. Apparently, stabilisation of vaterite by silica is much more efficient than at $200 \mathrm{ppm}$, such that merely small amounts of calcite are formed. Starting from 1200 and up to $5000 \mathrm{ppm} \mathrm{SiO}_{2}$, there are no longer significant temporal changes in $f_{\mathrm{V}}$ and $\alpha$, apart from an initial period of about 40 and $20 \mathrm{~min}$ at 1200 and $2000 \mathrm{ppm}$, respectively, during which the intensity of the calcite 104 reflection gradually increases before approximately constant values are obtained ( $c f$. Fig. $3 \mathrm{~b}$ and Section $\mathrm{S} 4$ in the ESI $\dagger$ ). The latter observation may originate from a retarded transformation of amorphous precursors (see below) to calcite (given that the area of vaterite peaks does not change simultaneously). Thus, all vaterite generated in the samples is effectively prevented from transforming into stable calcite in this range of silica concentrations, at least over the studied period of around 150 min after mixing. It is worth noting that the amount of vaterite co-existing with calcite in the systems is reduced from $>80 \%$ to $50-60 \%$ when increasing the silica content from 600 to 1200 ppm $\mathrm{SiO}_{2}$, whereas there is no clear trend in $f_{\mathrm{V}}$ recognizable between 1200 and $5000 \mathrm{ppm}$. This behaviour results from a competition between two opposing effects, namely the stabilisation of vaterite by silicate species and their promotion of calcite growth rates. In analogy to what was found at $20^{\circ} \mathrm{C}$, the latter phenomenon becomes enhanced starting from $1200 \mathrm{ppm}$, where both effects counterbalance and the mean fraction of vaterite varies only slightly up to $5000 \mathrm{ppm}$. Furthermore, since there was no distinct transformation of vaterite to calcite discernible in these samples and stabilisation of formed vaterite seems to be more or less quantitative, we suspect that the traced fraction of calcite grew directly from an initial ACC phase without involving vaterite as an intermediate. That is, silica favours the formation of calcite from ACC rather than accelerating the vaterite-to-calcite transition. In this context, it is worth elaborating on the possible role of $\mathrm{pH}$ in the kinetic stability of the vaterite phase. For example, Ogino et al. found a significant decrease in the rate of vaterite conversion to calcite at $50{ }^{\circ} \mathrm{C}$ 

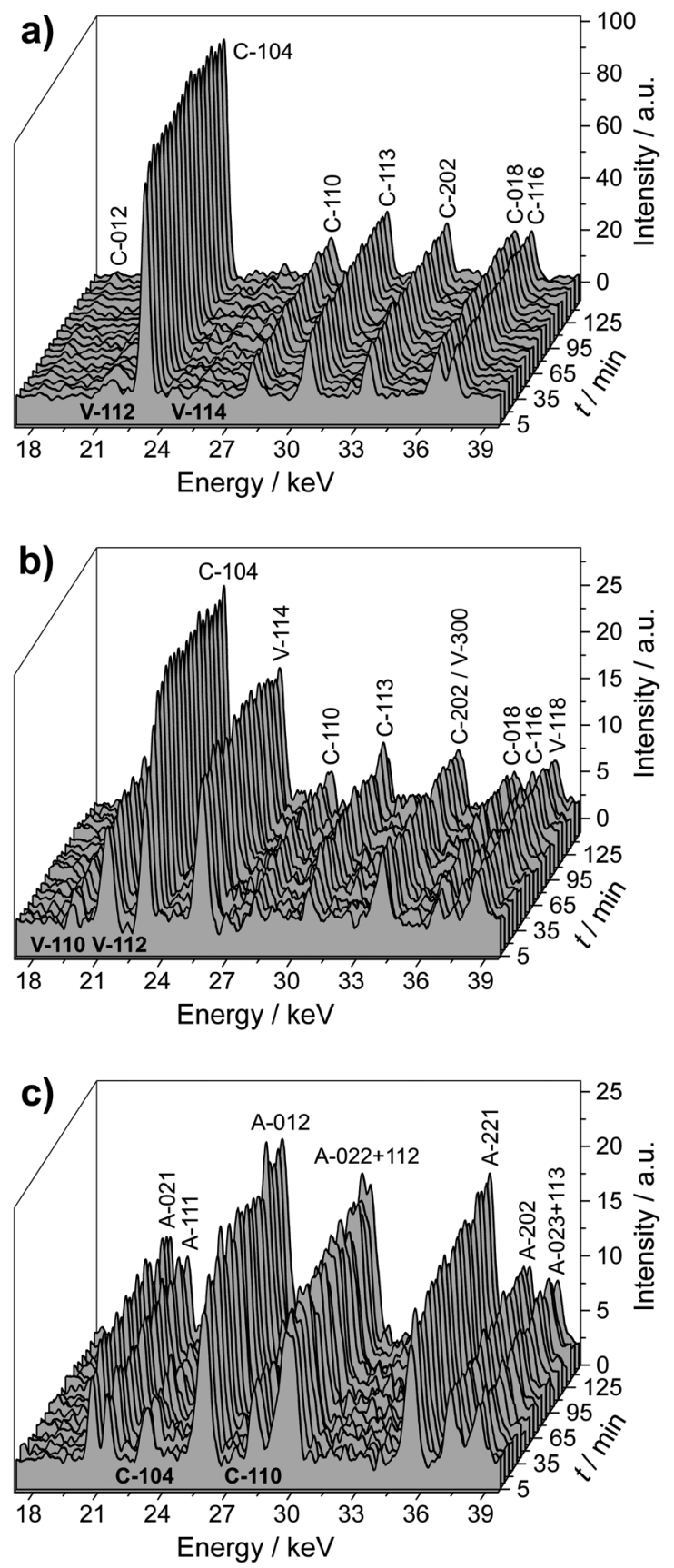

Fig. 3 Three-dimensional view of diffraction patterns acquired at different times from $\mathrm{CaCO}_{3}$ suspensions containing $1200 \mathrm{ppm} \mathrm{SiO}_{2}$ at (a) $20^{\circ} \mathrm{C}$, (b) $50^{\circ} \mathrm{C}$, and (c) $80^{\circ} \mathrm{C}$.

when the $\mathrm{pH}$ was increased well above 10 (while there was no marked change below); ${ }^{\mathbf{4 2}}$ in principle, this could be an alternative explanation for the prolonged endurance of vaterite in the present samples. Nevertheless, we exclude such a scenario since there was no vaterite stabilisation discernible under the same conditions at $20{ }^{\circ} \mathrm{C}$, and because the $\mathrm{pH}$ does not reach values beyond 10 at $\mathrm{SiO}_{2}$ contents lower than $5000 \mathrm{ppm}$ (whereas drastic inhibition of vaterite transformation was already observed at $1200 \mathrm{ppm}$ ). Moreover, we performed qualitative reference experiments, in which the $\mathrm{pH}$ was adjusted to 10-11 by addition of sodium hydroxide (no silica added), and did not trace any enhanced stability of vaterite under these circumstances.

Stabilisation of vaterite by soluble additives has been achieved in a number of previous studies, for instance by introducing foreign ions like sulfate, ${ }^{47}$ ammonium, ${ }^{48}$ lanthanum, ${ }^{49}$ or phosphate, ${ }^{50}$ using different water-alcohol mixtures as solvents, ${ }^{51}$ or by adding certain surfactants or polymers. ${ }^{52}$ In the latter case, the additives are thought to adsorb on the surface of nucleated crystallites and thereby stabilise them against ripening and phase transition. Presumably, dissolved silica acts in a similar way, protecting vaterite particles via adsorption or precipitation on their surface. The fact that silica-mediated stabilization of vaterite occurs at $50{ }^{\circ} \mathrm{C}$ but not at $20{ }^{\circ} \mathrm{C}$ can readily be understood on the basis of the temperature-dependent solution chemistry of silica. Although the equilibrium solubility of silica increases with temperature, ${ }^{26,53}$ condensation rates are higher and hence precipitation will proceed faster when solutions are heated, at least within the studied range of temperatures. ${ }^{54}$ Under kinetic control, silica condensation therefore yields higher oligomers in a shorter frame of time at $50{ }^{\circ} \mathrm{C}$ than at $20{ }^{\circ} \mathrm{C}$. The resulting polymeric species are expected to be much more suitable for adsorption on vaterite faces than small mono- or dimers commonly existing in solution at the given $\mathrm{pH}$ values. ${ }^{55}$ In an extreme case, reinforced condensation at higher temperatures may lead to the deposition of extended silica layers all over the carbonate crystallites, such that they become covered by a silica shell as observed previously under different conditions for ACC nanoparticles. ${ }^{33}$ Apart from temperature, the rate and degree of silica polymerisation generally depend also on concentration, $\mathrm{pH}$ and salinity of the system, with higher $\mathrm{SiO}_{2}$ contents and ionic strengths usually leading to faster condensation (more reactive species and better charge screening), ${ }^{56}$ whereas any concurrent increase in $\mathrm{pH}$ should have a slight opposite effect (stronger repulsion of individual units). ${ }^{26}$

$80{ }^{\circ} \mathrm{C}$. At $80{ }^{\circ} \mathrm{C}$, the influence of added silica is most prominent and becomes clearly manifest over the whole range of concentrations investigated. Indeed, diffraction patterns do no longer display any marked temporal evolution as soon as only $200 \mathrm{ppm} \mathrm{SiO}_{2}$ are present. This applies likewise for all other silica contents studied (see Fig. 3c and Section S4 in the ESI for additional data $\dagger$ ). Calculations of polymorphic ratios show that the fraction of aragonite is about $80-90 \%$ and remains more or less constant over the entire period of time monitored (Fig. 2c). This is in sharp contrast to the results obtained for the silicafree reference sample at $80{ }^{\circ} \mathrm{C}$, where gradual and eventually quantitative transformation of aragonite to calcite was observed (cf. Fig. 1c). Thus, silica is obviously also capable of stabilising aragonite as a kinetic crystalline product at $80^{\circ} \mathrm{C}$. Interestingly, the fraction of calcite in the silica-containing samples is about the same as in the reference without silica before transformation of aragonite sets in. This suggests that the initially generated fractions of the two polymorphs are not noticeably affected by the presence of silica; on the other hand, all aragonite formed during the early stages of precipitation appears to be stabilised by silica in the long term, such that the crystallisation process is virtually frozen soon after mixing. 
Stabilisation of aragonite at elevated temperature has previously been realised for example with the aid of cationic surfactants like $\mathrm{CTAB},{ }^{57}$ but also by means of adding silica: slow crystallisation of $\mathrm{CaCO}_{3}$ from alkaline silica sols at $80{ }^{\circ} \mathrm{C}$ gave nanocrystalline aggregates of aragonite, however only in relatively small amounts next to a predominant fraction of calcite. ${ }^{30}$ Analyses showed that the aragonite crystallites were interwoven by a matrix of amorphous silica, while other work provided evidence that some of them were individually sheathed by a siliceous skin. ${ }^{29}$ Precipitation of silica around forming aragonite particles thus is a scenario that may well account for the present results. The high efficiency of silica in preventing aragonite transformation as compared to the earlier experiments ${ }^{\mathbf{3 0}}$ is related to the higher supersaturation used in this work, and corresponding changes in $\mathrm{CaCO}_{3}$ precipitation and silica condensation kinetics.

It is furthermore evident that the conversion of the respective metastable crystalline phase into calcite is impeded in a substantially more effective manner at $80{ }^{\circ} \mathrm{C}$ than at $50{ }^{\circ} \mathrm{C}$, as much lower silica concentrations are sufficient to fully suppress transformation. This finding can be attributed to an additional increase in the condensation rate of silica when raising the temperature from $50{ }^{\circ} \mathrm{C}$ to $80{ }^{\circ} \mathrm{C}$.

\section{Stabilization of amorphous precursors at high silica contents}

$20{ }^{\circ} \mathbf{C}$. When the concentration of silica is increased to levels above $2000 \mathrm{ppm}$ at $20{ }^{\circ} \mathrm{C}$, calcite is the only crystalline phase detected by EDXRD, presumably due to accelerated growth rates caused by small silicate oligomers. However, unlike the data recorded at 1200 and 2000 ppm $\mathrm{SiO}_{2}$ ( $c f$. Fig. 2a and 3a), the diffraction patterns display noticeable temporal evolution again starting from $5000 \mathrm{ppm}$, where the intensity of calcite peaks increases over a certain frame of time rather than remaining constant from the beginning (Fig. 4a).

The period elapsed before no further changes occur was found to be longer the higher the silica concentration, ranging from about $20 \mathrm{~min}$ at $5000 \mathrm{ppm}$ over $40-45 \mathrm{~min}$ at $10000 \mathrm{ppm}$ to more than $120 \mathrm{~min}$ at $20000 \mathrm{ppm}$ ( $c f$. Fig. 4b). Since there are no reflections of other polymorphs discernible in the spectra at any time, the traced progressions reflect the gradual transformation of amorphous precursors into calcite. This suggests strongly that initially generated ACC particles are stabilised against rapid conversion at sufficiently high silica concentrations. Calculations of the reaction progress $\alpha$ demonstrate that the presence of silica also affects the final yield of calcite under these conditions (Fig. 4b): while conversion to calcite is eventually quantitative at $5000 \mathrm{ppm} \mathrm{SiO}_{2}$, only about $65 \%$ of the available $\mathrm{CaCO}_{3}$ material crystallises at $10000 \mathrm{ppm}$ and merely $14 \%$ of the ACC phase had transformed at the end of the experiment at $20000 \mathrm{ppm}$. This is consistent with light microscopy analyses of the precipitates after the measurements, which revealed well-defined calcite crystals in samples with silica contents of up to $5000 \mathrm{ppm}$. By contrast, an optically isotropic and almost translucent network with some embedded crystallites was obtained at both 10000 and 20000 ppm $\mathrm{SiO}_{2}$. These findings evidence that a distinct fraction of the nucleated
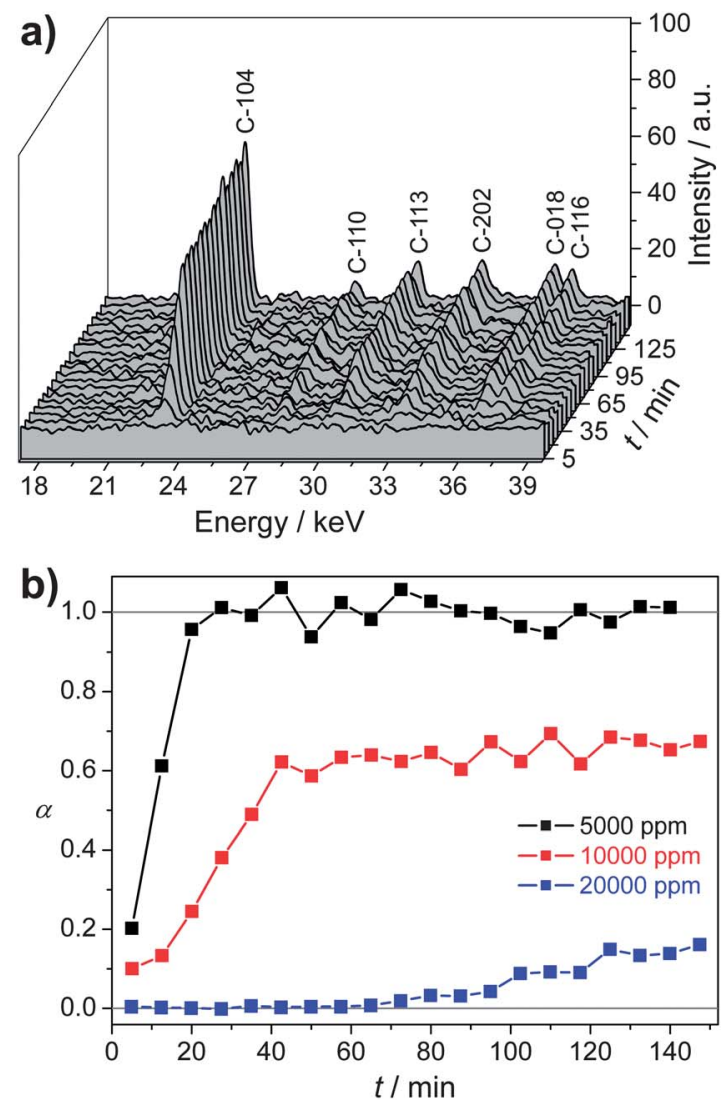

Fig. 4 (a) Time-dependent EDXRD profiles of a sample containing 10000 ppm $\mathrm{SiO}_{2}$ at $20^{\circ} \mathrm{C}$. (b) Degree of ACC transformation to calcite, expressed in terms of the reaction progress $\alpha$, as a function of time for mixtures with different silica contents at $20^{\circ} \mathrm{C}$.

ACC particles is temporarily stabilised by silica and converted to calcite with time at $5000 \mathrm{ppm}$, whereas a major part remains permanently protected against transformation at higher concentrations. Qualitatively, this is in good agreement with our previous study on $\mathrm{CaCO}_{3}$ crystallisation in more dilute systems, where silica-stabilised ACC and calcite co-existed in solution in the long term when $750 \mathrm{ppm} \mathrm{SiO}_{2}$ were added to suspensions containing $5 \mathrm{mM} \mathrm{CaCO}_{3}$ (i.e. for a Si/Ca molar ratio of 2.5). ${ }^{33}$ The relative amount of silica required to establish such a situation in the present systems is considerably lower $(\mathrm{Si} / \mathrm{Ca} \geq$ 0.5 ), possibly due to the distinct polymerisation behaviour of silica at drastically higher species concentrations.

Again, one may argue that differences in $\mathrm{pH}$ between the samples could affect the progress of crystallisation to a greater or lesser extent. Indeed, Koga et al. observed that, over a $\mathrm{pH}$ range of 11.2-13, the stability of ACC (assessed by thermal analyses) increases with the $\mathrm{pH}$ at which it was synthesised. ${ }^{58}$ This trend was ascribed to a decreasing degree of atomic order in the ACC materials and thus a larger energetic effort for its transformation to calcite with increasing $\mathrm{pH}$. Although we cannot fundamentally exclude a certain impact of the $\mathrm{pH}$ on the stability of ACC in the solutions studied here, it seems reasonable to assume that the presence of silica is the pivotal factor, because the $\mathrm{pH}$ is lower than 11 in all samples and, 
furthermore, analyses of precipitates formed at elevated $\mathrm{pH}$ in silica-free solutions did not indicate noticeable changes in the lifetime of ACC.

$50{ }^{\circ} \mathbf{C}$. At $50{ }^{\circ} \mathrm{C}$, distinct stabilisation of amorphous precursors can be distinguished only at the highest silica concentration investigated at this temperature $(10000 \mathrm{ppm})$. As at $20^{\circ} \mathrm{C}$, EDXRD patterns show an initial increase in the height of calcite signals, which is terminated after $20-30 \mathrm{~min}$ (see Fig. S2 in the $\mathrm{ESI} \dagger$ ). The area determined for the 104 reflection at later times is roughly constant and indicates that the final degree of transformation to calcite is about $45 \%$ in this case. Notably, calcite is the only crystalline phase generated under these conditions and vaterite no longer occurs as the metastable intermediate - in contrast to what was observed for lower silica concentrations at $50{ }^{\circ} \mathrm{C}$ ( $c f$. Fig. $2 \mathrm{~b}$ and $3 \mathrm{~b}$ ). Growth of calcite prevails over vaterite formation at $10000 \mathrm{ppm} \mathrm{SiO}_{2}$ because the promotional effect of silicate oligomers on the kink density of calcite faces drastically propels the corresponding growth rates. ${ }^{45}$ Therefore, the fraction of ACC which is only temporarily stabilised by silica will transform with strong preference directly to calcite, such that measurable quantities of vaterite do not exist at any stage of the crystallisation process and silicamediated stabilisation of vaterite cannot take place.

$80{ }^{\circ} \mathrm{C}$. Increasing the silica concentration to 5000 and 10000 ppm at $80{ }^{\circ} \mathrm{C}$ does not bring about any reinforced temporal variations in the EDXRD profiles. Still, the system seems to be frozen rapidly upon precipitation, with calcite and aragonite coexisting in roughly constant ratios in solution (see Section S4 in the ESI for diffraction data $\dagger$ ). However, when comparing patterns of samples with growing silica content at a given time, it is evident that aragonite signals are noticeably weaker at 5000 ppm and in particular at $10000 \mathrm{ppm} \mathrm{SiO}_{2}$ than at concentrations of 2000 ppm or lower (Fig. 5a). Integration of the aragonite 012 reflection shows that the amount of aragonite present is clearly reduced at 5000 and $10000 \mathrm{ppm} \mathrm{SiO}_{2}$, while there is also a slight decrease in the peak area between 200 and 2000 ppm; overall, the data can be reasonably well described by a linear fit (Fig. 5b). In parallel, the intensity of calcite reflections does not change significantly with the silica concentration and remains relatively low up to $10000 \mathrm{ppm}$ ( $c f$. Fig. 5a).

Thus, it can be inferred that a certain percentage of ACC is stabilised by silica at $80{ }^{\circ} \mathrm{C}$ starting from a concentration of $5000 \mathrm{ppm} \mathrm{SiO}_{2}$, and largely at the expense of formed aragonite. The corresponding values can be estimated on the basis of the known fraction of calcite out of the total amount of $\mathrm{CaCO}_{3}$ present $(\approx \alpha)$, and considering the data of the reference without silica at $80{ }^{\circ} \mathrm{C}$ (Fig. 2c), for which the fraction of aragonite can readily be calculated $(\approx 1-\alpha)$ when assuming that transformation of ACC in the absence of silica is quick and essentially completed before the end of the first measurement. The amount of aragonite existing in silica-containing samples at a given time can then be derived by relating the integrated intensity of aragonite reflections in these systems to that of the reference. The difference between the sum of the fractions of the two crystalline polymorphs and unity should eventually represent the amount of stabilised ACC. In this way, values of 0.38 and 0.65 were obtained for samples at 5000 and 10000
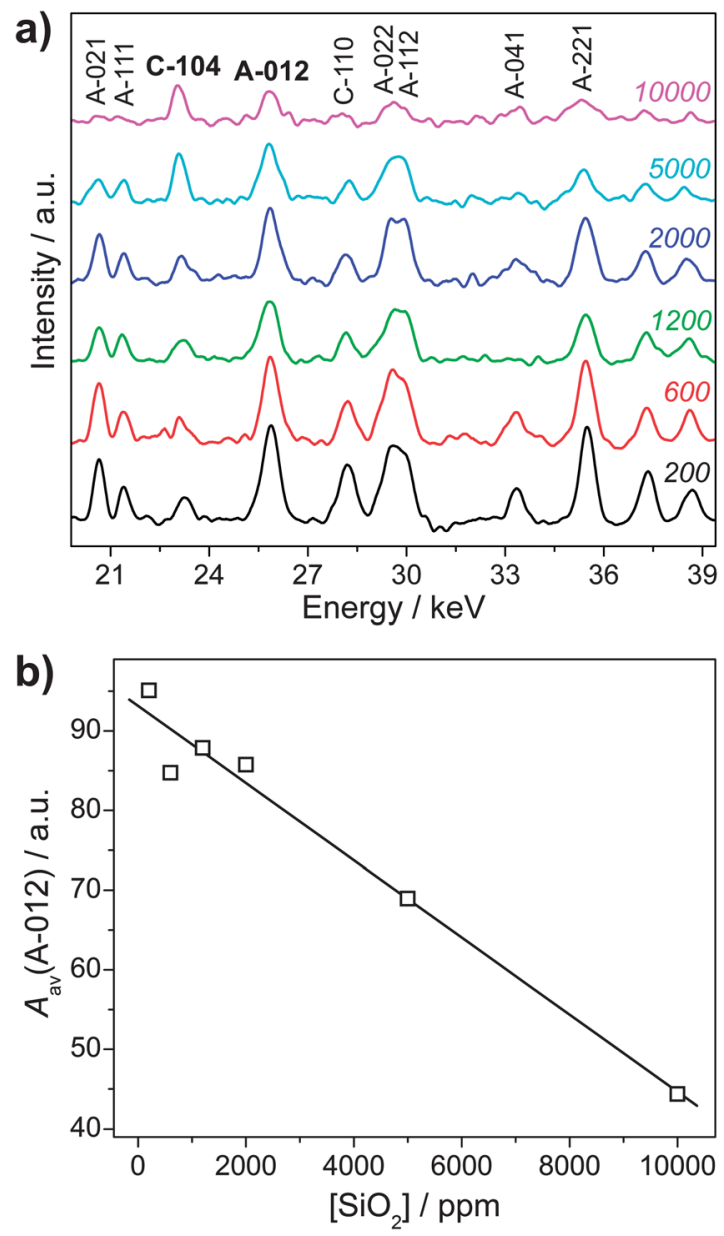

Fig. 5 (a) Sequence of diffraction profiles recorded from samples at $80^{\circ} \mathrm{C}$ and various silica contents. Patterns represent the final run of the measurement series in all cases (i.e. data were acquired over a period of $\sim 145$ to 150 min after mixing). (b) Plot of the integral area under the aragonite 012 reflection as a function of the silica concentration at $80{ }^{\circ} \mathrm{C}$. Black squares represent mean values of the peak area obtained by averaging over all 20 runs of each sample (note that there were no distinct changes with time in these systems), while the full line is a linear fit of the experimental data.

ppm $\mathrm{SiO}_{2}$, respectively. This means that, for a silica concentration of $10000 \mathrm{ppm}$, the percentage of ACC which remains permanently protected in solution is approximately $35 \%$ at $20{ }^{\circ} \mathrm{C}, 55 \%$ at $50{ }^{\circ} \mathrm{C}$, and $65 \%$ at $80{ }^{\circ} \mathrm{C}$. Hence, the capability of silica to stabilise ACC increases with temperature, most probably as a consequence of enhanced silica condensation rates, ${ }^{54}$ which promote local polymerisation around growing ACC particles and coating of the amorphous precursors as described previously. ${ }^{33}$

\section{Discussion}

Our experiments have shown that energy-dispersive X-ray diffraction is a powerful technique for tracing the crystallisation of calcium carbonate from solution and studying the multiple effects of additives in situ. In particular, for samples to which no silica was added, time-resolved diffraction patterns verify that vaterite occurs as a metastable crystalline intermediate at $20{ }^{\circ} \mathrm{C}$ 
as well as $50{ }^{\circ} \mathrm{C}$, whereas aragonite is kinetically favoured at $80^{\circ} \mathrm{C}$. Both polymorphs transform with time into stable calcite. This process could be directly monitored with the used setup. From the acquired data, the relative fractions of the different phases were calculated and, thus, the temporal progress of transformation was quantified. Results demonstrate that completed conversion to calcite takes longer at higher temperature, which is in line with previous work. ${ }^{6}$

Measurements performed with samples containing various amounts of silica proved a delicate influence of the additive on crystallisation scenarios. The most essential findings are summarised in Fig. 6 in the form of a temperature-concentration map visualising identified phases, on-going phase transformations, and time-dependent fractions of the distinct polymorphs under different conditions. Generally, silica affects $\mathrm{CaCO}_{3}$ crystallisation in two distinct ways. On the one hand, it impels growth rates of calcite, since low molecular-weight silica oligomers attach onto step edges and adsorbed polymeric particles additionally promote $2 \mathrm{D}$ nucleation, as described in detail elsewhere. ${ }^{45}$ This effect is most obvious at $20{ }^{\circ} \mathrm{C}$, where no more intermediate vaterite is observed at silica concentrations equal to or higher than $1200 \mathrm{ppm}$. It also accounts for the decrease in the fraction of vaterite between 600 and $1200 \mathrm{ppm}$ $\mathrm{SiO}_{2}$ at $50{ }^{\circ} \mathrm{C}$ and the fact that calcite is the only crystalline phase at $10000 \mathrm{ppm}$. On the other hand, the present experiments have shown that silica can furthermore stabilise all of the metastable $\mathrm{CaCO}_{3}$ polymorphs formed in the solutions. This feature is ascribed to adsorption and/or precipitation of silica on the carbonate particles, which inhibits transformation to calcite. Silica deposition on $\mathrm{CaCO}_{3}$ surfaces may derive from a local decrease in $\mathrm{pH}$ induced by growth of carbonates in alkaline media, as reported for the coating of ACC nanoparticles by silica shells in systems at lower supersaturation. ${ }^{33}$ The extent of stabilisation and the resulting polymorphic ratios intimately depend on both temperature and the silica concentration. Raising the temperature leads to an increase in the rate of silica condensation processes, such that higher oligomers (being more suitable for adsorption) are formed in a shorter frame of time and polymerisation/precipitation proceeds faster. Consequently, protection of metastable intermediates is more efficient at higher temperatures. This tendency becomes particularly manifest in the data at $80{ }^{\circ} \mathrm{C}$, where already 200 ppm $\mathrm{SiO}_{2}$ were found to largely suppress conversion of aragonite to calcite. By contrast, 600-1200 ppm are required for significant stabilisation of vaterite at $50{ }^{\circ} \mathrm{C}$, while no distinct stabilising influence of silica on vaterite could be distinguished at $20{ }^{\circ} \mathrm{C}$.

When more silica is added, the degree of transformation inhibition is in principle expected to be enhanced and yields larger amounts of metastable polymorphs in co-existence with calcite. However, this effect is counterbalanced by the simultaneous increase of calcite growth rates, which favour direct formation of calcite without an intermediate vaterite or aragonite phase. Nevertheless, the ability of silica to trap transient
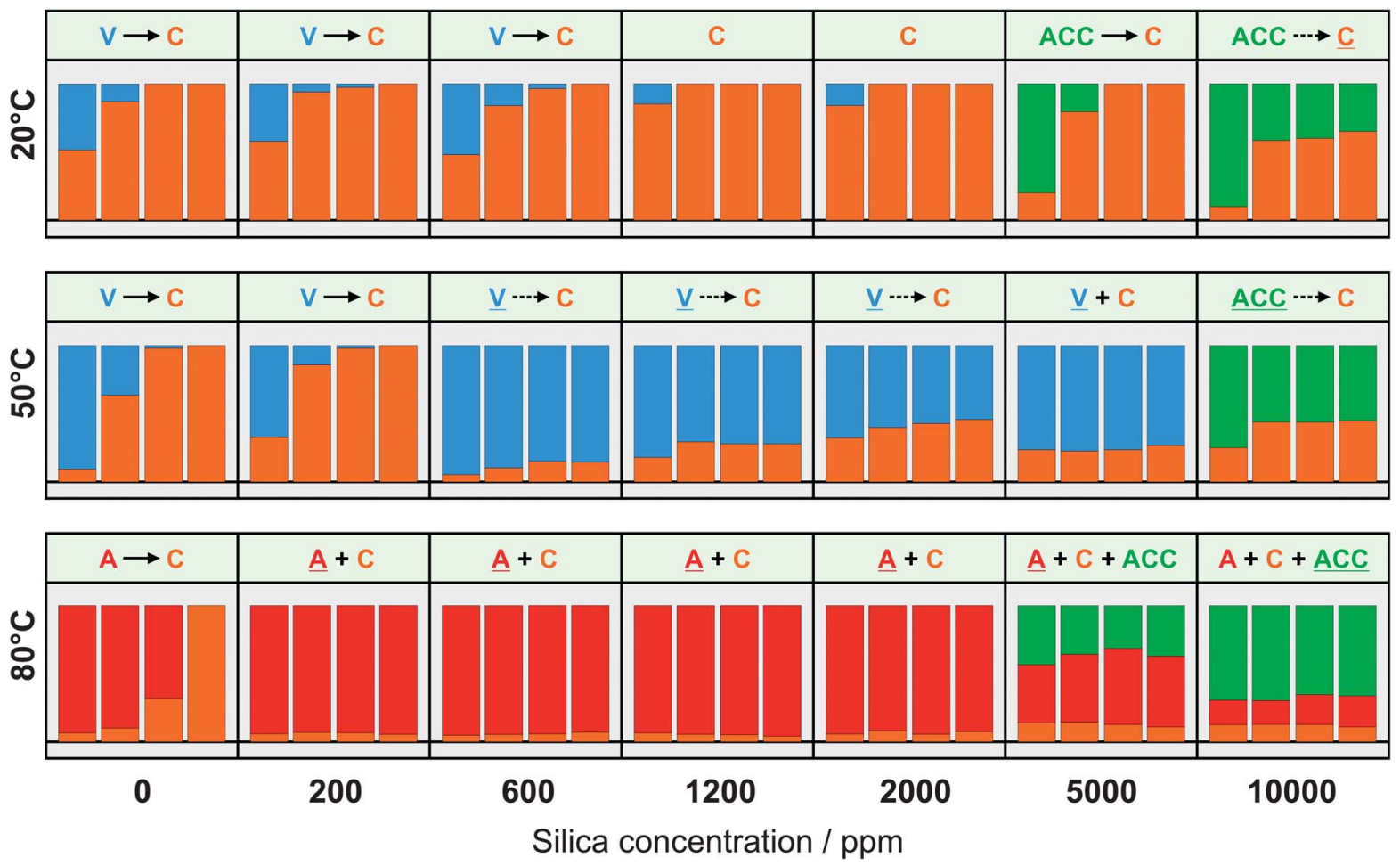

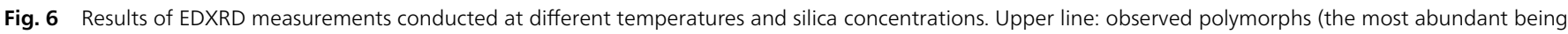

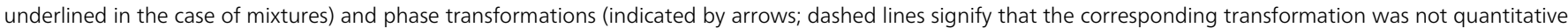

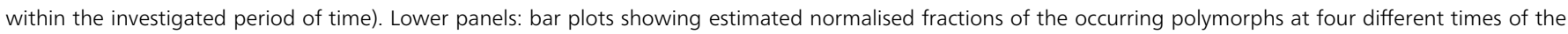
respective experiment: 5, 45, 90, and 140 min (from left to right in each panel). Colour code: orange - calcite, blue - vaterite, red - aragonite, green - ACC. 
$\mathrm{CaCO}_{3}$ phases becomes reinforced above a certain threshold in its concentration (typically between 5000 and 10000 ppm under the chosen conditions), where a considerable amount of amorphous calcium carbonate is stabilised either permanently (i.e. until the end of the experiments) or temporarily before being converted to calcite. This suggests that ACC is the initial solid phase formed upon nucleation, in agreement with results of previous in situ X-ray diffraction studies. ${ }^{\mathbf{1 0 , 3 7 - 4 1}}$ In the present systems, the lifetime of ACC is utterly short at low silica content, such that it cannot be traced at the given time resolution. In turn, at sufficiently high silica concentrations, transformation of ACC becomes slowed down or partially prevented, thus prolonging the endurance of the precursors in solution and rendering them experimentally detectable.

\section{Conclusions}

Our systematic study on the role of silica concentration and temperature in the polymorphic precipitation of calcium carbonate illustrates the various ways in which dissolved silicate species can interact with the different intermediates occurring in the course of precipitation from solution. The results show that the stability of the distinct polymorphs is affected by the presence of silica for the whole range of temperatures investigated. These findings are interesting for basic materials science, but also have important implications for practical applications, because the levels of silica concentration at which clear effects were observed are similar to those prevailing in many natural waters (potentially affecting $\mathrm{CaCO}_{3}$ precipitation in geochemical environments) as well as industrial processing solutions. ${ }^{59}$ For example, production of calcium carbonate materials is often carried out using aqueous solutions containing up to several hundreds of $\mathrm{ppm} \mathrm{SiO}_{2}$, and many of the waters forming scale in pipelines are likewise rich in silica ${ }^{60}$ Apart from that, interactions between forming calcium carbonate and silica may also occur in cements and concretes which, in contact with atmospheric carbon dioxide during hydration or $\mathrm{CO}_{2}$-containing fluids afterwards, are known to precipitate different $\mathrm{CaCO}_{3}$ polymorphs that deteriorate their performance. ${ }^{61}$ Our data might further be directly relevant to the field of $\mathrm{CO}_{2}$ sequestration, in particular for approaches relying on carbonation of calcium silicate minerals such as wollastonite. ${ }^{62}$ Leaching of $\mathrm{Ca}^{2+}$ and silicate ions from the mineral in solution-based routes leads to a situation where $\mathrm{CaCO}_{3}$ is mineralised under the influence of silica, quite similar to the conditions studied in this work. Finally, our results exemplify that EDXRD experiments can provide valuable information on the action of additives in crystallisation processes, and thus may be used to investigate the effects of various species on the precipitation of calcium carbonate as well as of other important minerals.

\section{Experimental Section}

\section{Sample preparation}

Crystallisation of calcium carbonate was induced by directly mixing $0.5 \mathrm{M}$ solutions of calcium chloride and sodium carbonate. Silica was introduced in the experiments by diluting commercial water glass in varying ratios with water and dissolving $0.5 \mathrm{M} \mathrm{Na}_{2} \mathrm{CO}_{3}$ in the resulting sols. The reaction was initiated by rapidly adding, with the aid of a graded pipette, $2.5 \mathrm{~mL}$ of $\mathrm{CaCl}_{2}$ to the same volume of $\mathrm{Na}_{2} \mathrm{CO}_{3}$ solution (no silica) or respectively mixtures of $\mathrm{Na}_{2} \mathrm{CO}_{3}$ and silica, placed in the vials together with a stirrer bar. Reagent solutions were equilibrated at the desired temperature for at least $2 \mathrm{~h}$ prior to the start of the experiment. Notably, the order of mixing was strictly maintained in this work as it proved to be, among other factors, essential for the reproducibility of the results, in line with previous work on $\mathrm{CaCO}_{3}$ precipitation $^{38}$ and as also observed for different systems. ${ }^{63}$ Final species concentrations in the samples were $250 \mathrm{mM}$ each of $\mathrm{CaCl}_{2}$ and $\mathrm{Na}_{2} \mathrm{CO}_{3}$, with silica contents of 0,200 , $600,1200,2000,5000,10000$, and 20000 ppm (corresponding to molar concentrations of $0,3.3,10.0,20.0,33.3,83.2,166.4$, and $332.9 \mathrm{mM}$, or $\mathrm{Si} / \mathrm{Ca}$ molar ratios of $0.013,0.040,0.080,0.133$, $0.333,0.666$, and 1.332). Straight after combining reagents, vials were closed firmly with a screw cap and turned upside down once to facilitate the mixing process. This was found to be important at $20{ }^{\circ} \mathrm{C}$ as the samples initially were gelatinous brines (due to $\mathrm{CaCO}_{3}$ (i.e. ACC) precipitation, ${ }^{\mathbf{3 8 , 4 0}}$ rather than silica gelation) and developed within few minutes into less viscous and stirrable slurries, while at higher temperatures a homogeneous suspension was achieved almost instantaneously.

\section{EDXRD experiments}

In situ diffraction measurements were performed at beamline F3 of the storage ring DORIS III at HASYLAB (DESY, Hamburg, Germany). It receives white synchrotron radiation from a bending magnet with a critical energy $E_{\mathrm{C}}$ of $16 \mathrm{keV}$ and a positron beam energy of $4.45 \mathrm{GeV}$. X-rays diffracted by a sample are traced by a nitrogen-cooled solid-state germanium detector with 2048 channels, which has an energy resolution $\Delta E / E$ of about 0.01 above 26 $\mathrm{keV}$ and can be positioned at horizontal angles of $0<2 \theta<30^{\circ}$ relative to the incident beam. The interval of energies observable with the chosen settings was found to range roughly from 6 to 52 $\mathrm{keV}$. To cover all relevant Bragg reflections of the different $\mathrm{CaCO}_{3}$ polymorphs, $2 \theta$ was adjusted to approximately $10^{\circ}$ in the present study, thus rendering $d$ spacings from about 1.37 to $12.1 \AA$ accessible. The incident beam was collimated to the sample with a tungsten double-slit system adjusted to $300 \times 300 \mu \mathrm{m}$, while a second slit system located in-between the sample and the detector (set to $200 \times 200 \mu \mathrm{m}$ for best results) served to reduce Compton scattering. As soon as the vial was mounted and X-rays were available, data acquisition was initiated. The delay between mixing and measurement start, usually being in the range of 1-2 min, was noted and accounted for in the evaluations. For all samples, diffraction was monitored in 20 subsequent runs, each averaging over a period of $450 \mathrm{~s}$ (which therefore is the net time resolution of the present experiments). Further details on experimental procedures and the used setup are given in Section S2 of the ESI. $\dagger$

\section{Acknowledgements}

The authors thank HASYLAB (DESY Hamburg) for granting access to beamline F3 and Thomas Wroblewski for technical 
support during beamtime. We are greatly indebted to André Rothkirch (HASYLAB) for his valuable help with the experiments and in particular for providing a software tool which allowed for quick and automated data evaluation. Roger-Jan Kutta (University of Regensburg) is acknowledged for programming routines that facilitated data processing and graphical illustration, Josef Eiblmeier (University of Regensburg) for carrying out some of the solution analyses. We are further grateful to Nicole Pienack, Beatrix Seidlhofer, Elena Antonova and Wolfgang Bensch (University of Kiel) for introducing us to beamline F3 and assistance in the course of the design and setup of the experiments. Financial support by BASF SE (M.K.), the program Juan de la Cierva of the Spanish Science Ministry (MICINN) (E.M.G.), the Consolider-Ingenio 2010 project "Factoria de Cristalización” and the MICINN project CGL2010-16882 (J.M.G.R.) is greatly appreciated.

\section{Notes and references}

1 F. Lippmann, Sedimentary carbonate minerals, Springer, Berlin, 1973.

2 H. A. Lowenstam and S. Weiner, On biomineralization, Oxford University Press, New York, 1989.

3 W. Tegethoff, J. Rohleder and E. Kroker, Calcium carbonate: from the cretaceous period to the 21st century, Birkhäuser, Basel, 2001.

4 J. MacAdam and S. A. Parsons, Rev. Environ. Sci. Biotechnol., 2004, 3, 159-169.

5 O. Söhnel and J. W. Mullin, J. Cryst. Growth, 1982, 60, 239250; S. L. Tracy, D. A. Williams and H. M. Jennings, J. Cryst. Growth, 1998, 193, 382-388.

6 T. Ogino, T. Suzuki and K. Sawada, Geochim. Cosmochim. Acta, 1987, 51, 2757-2767.

7 J. Rieger, T. Frechen, G. Cox, W. Heckmann, C. Schmidt and J. Thieme, Faraday Discuss., 2007, 136, 265-277.

8 W. S. Kim, I. Hirasawa and W. S. Kim, Ind. Eng. Chem. Res., 2004, 43, 2650-2657; J. Xiao, Z. Wang, Y. Tang and S. Yang, Langmuir, 2010, 26, 4977-4783; C. Kosanovic, G. Falini and D. Kralj, Cryst. Growth Des., 2011, 11, 269-277.

9 L. B. Gower and D. J. Odom, J. Cryst. Growth, 2000, 210, 719734; L. B. Gower, Chem. Rev., 2008, 108, 4551-4627.

10 S. E. Wolf, J. Leiterer, M. Kappl, F. Emmerling and W. Tremel, J. Am. Chem. Soc., 2008, 130, 12342-12347.

11 S. E. Wolf, L. Müller, R. Barrea, C. J. Kampf, J. Leiterer, U. Panne, T. Hoffmann, F. Emmerling and W. Tremel, Nanoscale, 2011, 3, 1158-1156.

12 D. Gebauer, A. Völkel and H. Cölfen, Science, 2008, 322, 1819-1822; D. Gebauer and H. Cölfen, Nano Today, 2011, 6, 564-584; E. M. Pouget, P. H. H. Bomans, J. A. C. M. Goos, P. M. Frederik, G. de With and N. A. J. M. Sommerdijk, Science, 2009, 323, 1455-1458.

13 A. Richter, D. Petzold, H. Hoffmann and B. Ullrich, Chem. Tech., 1996, 48, 271-275; S. Kabasci, W. Althaus and P. M. Weinspach, Chem. Eng. Res. Des., 1996, 74, 765-772; N. Spanos and P. G. Koutsoukos, J. Cryst. Growth, 1998, 191, 783-790; I. Sondi and E. Matijevic, J. Colloid Interface Sci., 2001, 238, 208-214; J. H. Kim, J. W. Ahn, H. S. Park and C. H. Park, Geosyst. Eng., 2004, 7, 95-102; M. Kitamura, Cryst. Eng. Commun., 2009, 11, 949-964.

14 J. L. Wray and F. Daniels, J. Am. Chem. Soc., 1957, 79, 20312034; J. Chen and L. Xiang, Powder Technol., 2009, 189, 64-69.

15 L. Wang, I. Sondi and E. Matijevic, J. Colloid Interface Sci., 1999, 218, 545-553.

16 D. Zhao, Y. Zhu, F. Li, Q. Ruan, S. Zhang, L. Zhang and F. Xu, Mater. Res. Bull., 2010, 45, 80-87.

17 M. Kitamura, H. Konno, A. Yasui and H. Masuoka, J. Cryst. Growth, 2002, 236, 323-332; R. S. Somani, K. S. Patel, A. R. Mehta and R. V. Jasra, Ind. Eng. Chem. Res., 2006, 45, 5223-5230.

18 J. Rieger, Tenside Surfactants Deterg., 2002, 39, 221-225.

19 H. Cölfen, Curr. Opin. Colloid Interface Sci., 2003, 8, 23-31; F. C. Meldrum and H. Cölfen, Chem. Rev., 2008, 108, 43324432.

20 L. Addadi and S. Weiner, Angew. Chem. Int. Ed., 1992, 31, 153-169; S. Mann, Biomineralization: principles and concepts in bioinorganic materials chemistry, Oxford University Press, Oxford, 2001; M. Cusack and A. Freer, Chem. Rev., 2008, 108, 4433-4454.

21 R. A. Berner, Geochim. Cosmochim. Acta, 1975, 39, 489-504; E. Loste, R. M. Wilson, R. Seshadri and F. C. Meldrum, J. Cryst. Growth, 2003, 254, 206-218; A. V. Radha, A. Fernandez-Martinez, Y. Hu, Y. Jun, G. A. Waychunas and A. Navrotsky, Geochim. Cosmochim. Acta, 2012, 90, 8395; D. Wang, L. H. Hamm, A. J. Giuffre, T. Echigo, J. D. Rimsidt, J. J. de Yoreo, J. Grotzinger and P. M. Dove, Faraday Discuss., 2012, 159, 371-386.

22 J. Aizenberg, G. Lambert, S. Weiner and L. Addadi, J. Am. Chem. Soc., 2002, 124, 32-39; Y. Ma, B. Aichmayer, O. Paris, P. Fratzl, A. Meibom, R. A. Metzler, Y. Politi, L. Addadi, P. U. P. A. Gilbert and S. Weiner, Proc. Natl. Acad. Sci. U. S. A., 2009, 106, 6048-6053; C. E. Killian, R. A. Metzler, Y. U. T. Gong, I. C. Olson, J. Aizenberg, Y. Politi, F. H. Wilt, A. Scholl, A. Young, A. Doran, M. Kunz, N. Tamura, S. N. Coppersmith and P. U. P. A. Gilbert, J. Am. Chem. Soc., 2009, 131, 1840418409; D. Wang, A. F. Wallace, J. J. de Yoreo and P. M. Dove, Proc. Natl. Acad. Sci. U. S. A., 2009, 106, 2151121516; Y. Politi, D. R. Batchelor, P. Zaslansky, B. F. Chmelka, J. C. Weaver, I. Sagi, S. Weiner and L. Addadi, Chem. Mater., 2010, 22, 161-166.

23 W. A. Deer, R. A. Howie and J. Zussman, An introduction to the rock forming minerals, Longman, London, 1992.

24 C. C. Perry, Rev. Mineral. Geochem., 2003, 54, 291-327; M. Sumper and E. Brunner, Adv. Funct. Mater., 2006, 16, 17-26.

25 P. Treguer, D. M. Nelson, A. J. van Bennekom, D. J. DeMaster, A. Leynaert and B. Queguiner, Science, 1995, 268, 375-379; J. M. Garcia-Ruiz, Geology, 1998, 26, 843-846.

26 R. K. Iler, The chemistry of silica, Wiley, New York, 1979.

27 U. K. Mader, T. Fierz, B. Frieg, J. Eikenberg, M. Ruthi, Y. Albinsson, A. Mori and S. Eiberg, J. Geochem. Explor., 2005, 90, 68-94. 
28 S. Dominguez-Bella and J. M. Garcia-Ruiz, J. Cryst. Growth, 1986, 76, 236-240; S. Dominguez-Bella and J. M. GarciaRuiz, J. Mater. Sci., 1987, 22, 3095-3102; H. Imai, T. Terada and S. Yamabi, Chem. Commun., 2003, 484-485; R. Lakshminarayanan and S. Valiyaveettil, Cryst. Growth Des., 2003, 3, 611-614.

29 H. Imai, T. Terada, T. Miura and S. Yamabi, J. Cryst. Growth, 2002, 244, 200-205.

30 A. E. Voinescu, M. Kellermeier, B. Bartel, A. M. Carnerup, A. K. Larsson, D. Touraud, W. Kunz, L. Kienle, A. Pfitzner and S. T. Hyde, Cryst. Growth Des., 2008, 8, 1515-1521.

31 Y. Kitano, M. Okumura and M. Idogaki, Geochem. J., 1979, 13, 253-260.

32 L. Z. Lakshtanov and S. L. S. Stipp, Geochim. Cosmochim. Acta, 2010, 74, 2655-2664.

33 M. Kellermeier, E. Melero-Garcia, F. Glaab, R. Klein, M. Drechsler, R. Rachel, J. M. Garcia-Ruiz and W. Kunz, J. Am. Chem. Soc., 2010, 132, 17859-17866.

34 M. Kellermeier, E. Melero-Garcia, W. Kunz and J. M. GarciaRuiz, Adv. Chem. Phys., 2012, 151, 277-307.

35 A. Gal, S. Weiner and L. Addadi, J. Am. Chem. Soc., 2010, 132, 13208-13211.

36 M. Kellermeier, D. Gebauer, E. Melero-Garcia, M. Drechsler, Y. Talmon, L. Kienle, H. Cölfen, J. M. Garcia-Ruiz and W. Kunz, Adv. Funct. Mater., 2012, 22, 4301-4311.

37 J. D. Rodriguez-Blanco, S. Shaw and L. G. Benning, Nanoscale, 2011, 3, 265-271.

38 J. D. Rodriguez-Blanco, S. Shaw, P. Bots, T. Roncal-Herrero and L. G. Benning, J. Alloys Compd., 2012, 536, S477-S479.

39 E. L. Heeley, C. K. Poh, W. Li, A. Maidens, W. Bras, I. P. Dolbnya, A. J. Gleeson, N. J. Terrill, J. P. A. Fairclough, P. D. Olmsted, R. I. Ristic, M. J. Hounslow and A. J. Ryan, Faraday Discuss., 2002, 122, 343-361.

40 T. Chen, A. Neville, K. Sorbie and Z. Zhong, Faraday Discuss., 2007, 136, 355-365.

41 S. E. Wolf, J. Leiterer, V. Pipich, R. Barrea, F. Emmerling and W. Tremel, J. Am. Chem. Soc., 2011, 133, 12642-12649.

42 T. Ogino, T. Suzuki and K. Sawada, J. Cryst. Growth, 1990, 100, 159-167.

43 D. Kralj, L. Brecevic and J. Kontrec, J. Cryst. Growth, 1997, 177, 248-257.

44 L. N. Plummer and E. Busenberg, Geochim. Cosmochim. Acta, 1982, 46, 1011-1040.

45 C. M. Pina, C. Merkel and G. Jordan, Cryst. Growth Des., 2009, 9, 4084-4090.

46 J. W. Morse, R. S. Arvidson and A. Lüttge, Chem. Rev., 2007, 107, 342-381.

47 L. Fernandez-Diaz, A. Fernandez-Gonzalez and M. Prieto, Geochim. Cosmochim. Acta, 2010, 74, 6064-6076.

48 N. Gehrke, H. Cölfen, N. Pinna, M. Antonietti and N. Nassif, Cryst. Growth Des., 2005, 5, 1317-1319.
49 H. Tsuno, H. Kagi and T. Akagi, Bull. Chem. Soc. Jpn., 2001, 74, 479-486.

50 A. Katsifaras and N. Spanos, J. Cryst. Growth, 1999, 204, 183190.

51 F. Manoli and E. Dalas, J. Cryst. Growth, 2000, 218, 359364.

52 H. Cölfen and M. Antonietti, Langmuir, 1998, 14, 582589; Q. Shen, L. Wang, Y. Huang, J. Sun, H. Wang, Y. Zhou and D. Wang, J. Phys. Chem. B, 2006, 110, 23148-23153; H. Wei, Q. Shen, H. Wang, Y. Gao, Y. Zhao, D. Xu and D. Wang, J. Cryst. Growth, 2007, 303, 537-545; A. Szczes, E. Chibowski and L. Holysz, Colloids Surf., A, 2007, 297, 14-18.

53 G. B. Alexander, W. M. Heston and R. K. Iler, J. Am. Chem. Soc., 1953, 75, 5655-5657.

54 G. B. Alexander, J. Am. Chem. Soc., 1953, 76, 2094-2096; S. A. Greenberg and D. Sinclair, J. Phys. Chem., 1955, 59, 435-440; D. J. Belton, O. Deschaume, S. V. Patwardhan and C. C. Perry, J. Phys. Chem. B, 2010, 114, 9947-9955.

55 S. Sjöberg, J. Non-Cryst. Solids, 1996, 196, 51-57.

56 G. A. Icopini, S. L. Brantley and P. J. Heaney, Geochim. Cosmochim. Acta, 2005, 69, 293-303.

57 J. Yu, M. Lei, B. Cheng and X. Zhao, J. Cryst. Growth, 2004, 261, 566-570.

58 N. Koga, Y. Nakagoe and H. Tanaka, Thermochim. Acta, 1998, 318, 239-244.

59 E. K. Berner and R. A. Berner, Global environment: water, air and geochemical cycles, Prentice Hall, Upper Saddle River, NJ, 1996.

60 R. Sheikholeslami and S. Tan, Desalination, 1999, 126, 267280; T. Koo, Y. J. Lee and R. Sheikholeslami, Desalination, 2001, 139, 43-56; P. Sahachaiyunta, T. Koo and R. Sheikholeslami, Desalination, 2002, 144, 373-378; W. S. Midkiff and H. P. Foyt, Mater. Perform., 1978, 17, 1722; J. S. Gill, Mater. Perform., 1998, 37, 41-45.

61 E. T. Stepkowska, J. L. Perez-Rodríguez, M. J. Sayagues and J. M. Martinez-Blanes, J. Therm. Anal. Calorim., 2003, 73, 247-269; O. Shtepenko, C. Hills, A. Brough and M. Thomas, Chem. Eng. J., 2006, 118, 107-118; M. Palacios and F. Puertas, J. Am. Ceram. Soc., 2006, 89, 3211-3221; N. Jacquemet, J. Pironon and J. Saint-Marc, Environ. Sci. Technol., 2008, 42, 282-288.

62 W. J. J. Huijgen, G. J. Witkamp and R. N. J. Comans, Chem. Eng. Sci., 2006, 61, 4242-4251; D. Daval, I. Martinez, J. M. Guigner, R. Hellmann, J. Corvisier, N. Findling, C. Dominici, B. Goffe and F. Guyot, Am. Mineral., 2009, 94, 1707-1726; D. Daval, I. Martinez, J. M. Guigner, R. Hellmann, J. Corvisier, N. Findling, B. Goffe and F. Guyot, Chem. Geol., 2009, 265, 63-78.

63 E. I. Howard, J. M. Fernandez and J. M. Garcia-Ruiz, Cryst. Growth Des., 2009, 9, 2707-2712. 